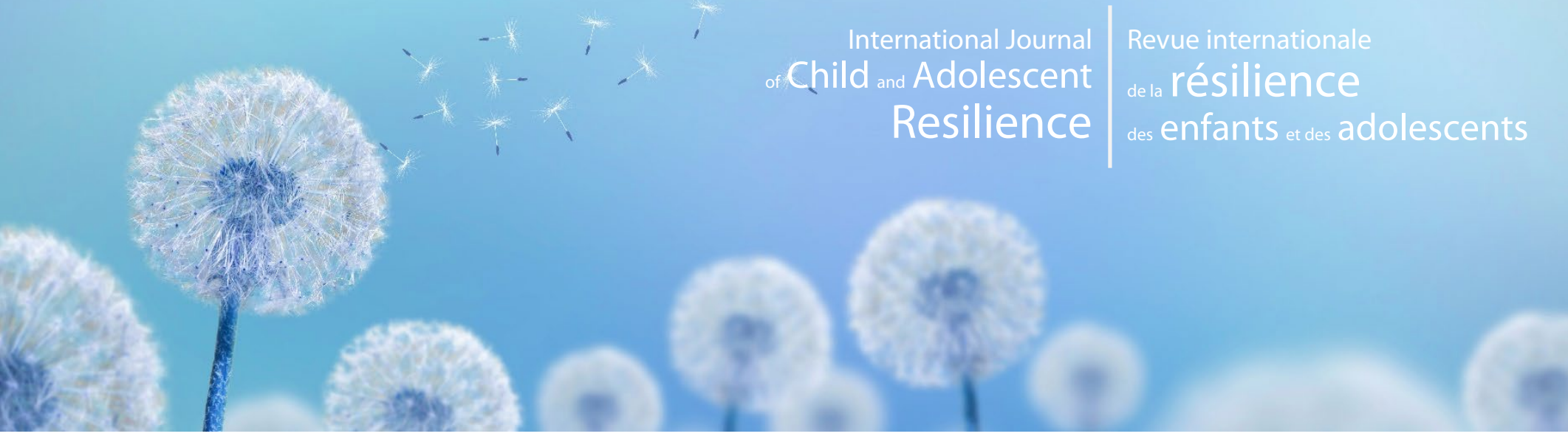

\title{
Trauma-informed care in child welfare: An imperative for residential childcare workers
}

\section{Denise Michelle BREND' and Ginny SPRANG ${ }^{2}$}

1 Centre for Research on Children and Families, McGill University, Montréal, Québec

2 Center on Trauma and Children and University of Kentucky, Lexington, Kentucky

Corresponding Author: Denise Michelle Brend, Ph.D., Centre for Research on Children and Families, McGill University, Suite 106, Wilson Hall, 3506 University Street, Montreal, Québec, Canada H3A 2 A7.

Email: flo.d.brend@mail.mcgill.ca.

\section{Abstract}

Context: Rates of traumatization among residential child welfare professionals are alarmingly high. The well-being of these professionals is associated both with their intention to stay in their jobs and outcomes of children in their care. Several risk factors threaten the well-being of child welfare professionals, including primary and secondary exposure to experiences with the potential to provoke posttraumatic stress reactions.

Objectives: This manuscript details experiences empirically shown to have potential negative impacts on professional well-being, discusses why these impacts are of particular concern for residential childcare workers, and describes the types of organizational cultures and climates that appear to mitigate these negative impacts.

Implications: Trauma-informed care at the organizational level is proposed both as a means to reduce harm to childwelfare professionals and promote the rehabilitation of children within the child welfare system.

Keywords: Residential childcare workers; secondary traumatic stress; trauma-informed care; child welfare; educators. 


\section{Introduction}

The well-being of residential childcare workers $(\mathrm{RCWS})^{1}$ is associated with professional turnover, intention to leave, and the outcomes of children and youth in their care. This manuscript details experiences empirically shown to have potential negative impacts on RCW well-being; discusses why these impacts are pertinent among RCWs and the children and youth they serve; describes promising organizational strategies to mitigate potential negative impacts; proposes the implementation of TIC at the organizational level as a double-pronged strategy to promote the recovery of children and youth within the child welfare system, and to reduce harm to the well-being child-welfare professionals.

\section{Residential Child Welfare Work: Impacts of treating trauma exposed children}

Residential childcare workers (RCWs) are routinely exposed to children's experiences of maltreatment and neglect (Caringi \& Hardiman, 2011; Cornille \& Meyers, 1999; Pryce et al., 2007; Regehr et al., 2005). Such exposure to potentially traumatic experiences can not only influence professional intent to leave, but also reduce RCWs capacity to fully engage in helping relationships with the children in their care (Middleton \& Potter, 2015; Pryce et al., 2007). Intention to leave child welfare practice contributes to workforce instability in the child welfare system, which has been associated with shorter lengths of placements, more placements in the future, and other negative impacts for children in care (Hébert et al., 2016; Strolin-Goltzman et al., 2010; Tremblay et al., 2016). Difficulties retaining professionals in the child welfare system also contribute to high financial costs and reduced service capacity (Boyas et al., 2012; Chernesky \& Israel, 2009; Graef \& Hill, 2000; Itzick \& Kagan, 2017; Madden et al., 2014; McGowan et al., 2009; Mor Barak et al., 2001; Nissly et al., 2005; Tollen, 1960). Many additional factors impacting the intent of child welfare professionals to leave their positions have been identified: burnout; personal commitment; self-efficacy; demographic characteristics; availability and efficacy of supervision; job satisfaction; organizational commitment; general organizational practices; caseload size; salary issues; and, moral distress (Brend et al., 2020; Strolin et al., 2006). Scholars have also examined how on-the-job violence impacts child welfare workers. Physical assault and threats made by children or their family members are violent acts found to be routinely encountered by RCWs (Geoffrion \& Ouellet, 2013; Lamothe et al., 2018; Littlechild, 2005; Robson et al., 2014; Shin, 2011; Van Hook \& Rothenberg, 2009). The pervasiveness of such violence has been associated with impacts to RCWs and other child welfare professionals' psychological well-being, loss of motivation, turnover intention, sick leaves, and emotional detachment from, or avoidance of, clients (Geoffrion \& Ouellet, 2013; Lamothe et al., 2018). Preventing and reducing the potentially harmful impacts of exposure to traumatic experiences among RCWs is of central importance towards promoting strong helping relationships, reducing voluntary turnover, and strengthening outcomes for children in residential care.

Children placed in residential treatment have high rates of exposure to many adverse experiences. Among Canadian children aged 7-15 placed in residential child welfare settings as a result of an estimated 2182 maltreatment investigations, maltreatment was confirmed for 83\%, suspected for 7\%, and not verified for 10\% (DuRoss et al., 2019). Maltreatment included physical and sexual abuse, neglect, emotional maltreatment, and exposure to domestic violence. Such experiences during early childhood, specifically within caregiving relationships and over time, are termed "complex trauma" (Cook et al., 2005; Pearlman \& Courtois, 2005; van der Hart et al., 2005; van der Kolk et al., 2005). Children impacted by complex trauma can meet the diagnostic criteria for post-traumatic stress disorder (PTSD), a mental health issue characterized by symptoms such as extreme and prolonged distress, uncomfortable affect (irritability, anger, fear, guilt), inability to feel pleasurable emotions (happiness, satisfaction, love), and negative beliefs about the self (American Psychiatric Association [APA], 2013b). Reactive Attachment Disorder and Disinhibited Social Engagement Disorder are also more common among these children. The former being characterized by a lack of engagement in relationships with caregivers and the latter by an overly familiar engagement with unknown adults (APA, 2013c). Additionally, data reported for 1699 children and youth (aged 0-21) shows these children often have disturbances in multiple developmental domains, including affect regulation, attention and concentration, impulse control, aggression or risk taking, somatization, conduct or oppositionality, age-inappropriate sexual interest, activity or avoidance, attachment, or dissociation (Spinazzola et al., 2005). The adversity children experience can impact their health, behaviour, and social capacities. These complex and challenging impacts can require specialized rehabilitative treatment in residential child welfare settings.

\footnotetext{
${ }^{1}$ RCWs are helping professionals working in residential child-welfare and youth justice settings such as group homes and rehabilitation facilities.
} 
It is also highly likely that children in placement without confirmed maltreatment reports have nonetheless been exposed to other forms of adverse experience. Returning to the $17 \%$ of Canadian children in placements without substantiated maltreatment, researchers hypothesized that the majority of those placements resulted from voluntary care agreements (Child Welfare Research Portal, 2010). Such agreements are often struck when parents or caregivers are unable to manage their children's behavioural or emotional needs. Indeed, $81 \%$ of all children in placement were reported to have behaviour problems, and $70 \%$ had physical, emotional, or cognitive problems. There is mounting evidence that children identified as having behavioural issues, are at high risk of abuse, neglect, or other traumatic exposures (Baglivio, 2018; Ford et al., 2012). DuRoss et al. (2019) found multiple potential risk factors for traumatic exposures other than maltreatment related to the caregivers of children in residential care. The parents of children in care were reported to have few social supports (40\%), experience intimate partner violence (35\%), suffer from mental health issues (34\%), have a substance abuse issue (28\%) and to have their own history of maltreatment as a child (28\%). Each of these parental risk factors has been positively associated with the sequalae of complex trauma in children (Catalan et al., 2017; Felitti et al., 1998; Lünnemann et al., 2019). Indeed, the strongest predictors of adult PTSD include trauma severity, life stress, lack of social support, and peritraumatic psychological processes (Brewin et al., 2000; Ozer et al., 2003). Taken together, these findings suggest that all children placed in residential care might benefit from a therapeutic approach designed for the rehabilitation of post-traumatic stress and developmental disturbances. Indeed, involvement in the child welfare system itself can either promote the resilience of at-risk children or contribute further to the risks they face (Ungar, 2005).

Trauma Informed Care (TIC) necessitates that organizational practices and policies are driven by a large data base of trauma-focused research that can be used to establish practice standards. Fortunately, the trauma literature is appropriately nuanced to consider the developmental needs of children across the lifespan, and provides appropriate guidance on how screening, assessment, practice and the service delivery context should be adapted in an age and skill-based manner. This empirically driven developmental tailoring and contextualizing, guided by the trauma informed care perspective, prevents harm to those who may otherwise be subjected to interventions or practices that are not matched to their needs.

Broad consensus among experts treating children and youth impacted by complex, or interpersonal trauma, is that the most effective therapeutic responses occur within culturally relevant, secure interpersonal relationships (Blaustein \& Kinniburgh, 2018; Brandt et al., 2014; Briere \& Scott, 2015; Courtois \& Ford, 2013; Ford, 2014; Strand \& Sprang, 2018; Ungar, 2013). Early childhood development takes place within the context of attachment relationships, therefore the quality of the attachment relationships a child has impacts their development (Beebe \& Lachman, 2002; Bowlby, 1988; Fonagy \& Campbell, 2015). For children impacted by complex trauma, their capacity to integrate traumatic selfstates and events, and recover typical development is strongly associated with their access to a secure caregiver (Blaustein \& Kinniburgh, 2018). Therefore, the professionals who care for children placed in residential settings day-today are in key positions to act as secure bases. In this role, RCWs have a unique capacity to serve as potential professional attachment figures for these children (Brend et al., 2013). Paradoxically, this relational proximity to the children in their care also puts RCWs at risk of harmful impacts associated with secondary exposure to adverse experiences-feeding the cycle of workforce instability. Most trauma-informed evidence-based practices that could be delivered in residential settings involve the creation and processing of a trauma narrative, or other exposure-based techniques that may intensify indirect transmission of traumatic material.

\section{Understanding secondary exposure to adverse experiences among RCWs}

A search of six databases (Soclndex, Psyclnfo, CINAHL, Cochrane, Social Services Abstracts, Social Work Abstracts, Google Scholar) up to and including 2019 returned 970 results using the keywords "child welfare", "youth protection", "child protection", "vicarious trauma", "compassion fatigue", "secondary trauma*". Narrowing the inclusion criteria to empirical, peer-reviewed studies with aims related to the well-being of RCWs, this number dwindles to eleven available publications. While there is very limited empirical literature related to post-traumatic stress among RCWs, elevated rates of traumatization have been shown among diverse human service professionals in related professional roles. Captured using various concepts that employed the same, or similar, diagnostic features as PTSD-the adverse impacts of exposure to client trauma have been termed vicarious traumatization, compassion fatigue, and secondary traumatic stress disorder (APA, 2013a; Figley, 1995; McCann \& Pearlman, 1990; Stamm, 1995). For clarity, all study of harmful impacts related to professional exposure to the adverse experiences of clients is here grouped under the term secondary traumatic stress (STS) as proposed by Molnar et al. (2017). Contrasting the STS rates of human service professionals with rates of PTSD in the general population offers dimension to the manifestation of traumatization 
among human service professionals. To elaborate, the prevalence rate of PTSD at age 75 in the general population is 8.7\% (Kessler et al., 2005). In contrast, among human service professionals the following cross-sectional rates of traumatization have been reported: Social workers, 15\% (Bride, 2007); Social workers working with survivors of family or sexual violence, 29\% (Choi, 2011b); Southern American child protective workers, 37\% (Cornille \& Meyers, 1999); Domestic violence advocates, 43.7\% (Slattery \& Goodman, 2009); Children's Aid social workers in Toronto at intake, 52\%, in family services, 64\% and, in children's services, 75\% (Regehr et al., 2005). Audin et al. (2018) sampled 100 professionals working in residential child welfare settings in the United Kingdom (including management and administration) and found a rate of 26\%; Borjanić Bolić (2019) sampled 36 Serbian residential services workers and found a rate of 15\%. Elevated rates of traumatization among these two international samples coupled with elevated rates among diverse professionals in similar professional roles suggest that RCWs occupy an occupational group at elevated risk of STS.

Child welfare work has long been recognized as a risky occupation (Cieslak et al., 2014; Lakin et al., 2008; McElvaney \& Tatlow-Golden, 2016; Pryce et al., 2007). Using statistical comparisons, Sprang et al. (2011) found that reported occupation as a child welfare worker was more likely to be independently correlated with elevations in secondary trauma and burnout, controlling for other types of behavioral healthcare professional groups. In efforts to understand why some professionals were harmed while others not, Hiles Howard et al. (2015) examined relationships between professional quality of life, adverse childhood experiences (ACEs), resilience, and work environment in a sample of child welfare professionals working in the foster care system. Participants in their study did have elevated rates of multiple ACEs compared to normative sample data for the general population (4 or more ACEs: 25.1\% v. 12.5\%). Contrary to their hypothesis however, there was no relationship between ACE history and STS. Indeed, as a group those with higher ACEs were found to have elevated professional quality of life. Findings are mixed regarding the influence of prior personal trauma on STS among human service professionals. Kassam-Adams (1998) showed childhood trauma as predictive of STS while others failed to show a direct relationship between child or adult trauma history and STS (Bober \& Regehr, 2006; Follette et al., 1994; Schauben \& Frazier, 1995). Returning to Hiles Howard et al. (2015), factors predictive of poor professional quality of life were "low levels of resilience and controlling organizational leadership" ( $p$. 141). In another study drawing child welfare workers in community-based care organizations in central Florida, Van Hook and Rothenberg (2009) found that younger workers and those more exposed to potentially traumatic experiences, including supervisors, were at the highest risk; and, realistic caseloads and administrative support were identified by their participants as lacking. Van Hook and associates also identified younger age as a risk factor for STS. Furthermore, Hiles et al. (2015) identified parenthood, being in a significant relationship, and job tenure as potentially protective against traumatization. These findings suggest that either the job gets easier with age and with a supportive social network outside of work, or that the professionals who stayed in the profession were those equipped with the necessary resilience factors.

Individual risk factors and behaviours may also be involved in STS. Throughout the lifespan attachment styles influence personal capacities to manage challenges. Investigating the role of personality resources among diverse human services samples and including RCWs, Zerach (2013) conducted a systemic review aiming to synthesize and clarify findings related to adult attachment styles and burnout and/or compassion fatigue (STS). These concepts have been found to be highly co-related, thus it is unsurprising that the relationships identified between these constructs and attachment security were the same: higher attachment security being associated with lower levels of each and lower attachment security being associated with higher levels of each (West, 2015). Eastwood and Ecklund (2008) sampled RCWs because of their unique position in close, long term contact with youth in care and concluded that burnout (being stressed and overwhelmed) contributed to compassion fatigue (STS); compassion satisfaction (or finding value and meaning in one's work) did not correlate with compassion fatigue, while supportive relationships outside of work were protective. This study also investigated self-care, finding and engaging in a hobby, reading for pleasure, and taking pleasure trips or vacations to be significant negative correlates or identified protective factors. It may be that reading, hobbies, and trips were protective, or that all three of these experiences labelled as self-care were confounded with having fewer demands on one's time, financial resources, and a supportive network outside of work. Indeed, studies sampling child welfare workers have demonstrated STS levels were not reduced through self-care practices (Bober \& Regehr, 2006; Salloum et al., 2015). Thus, self-care activities may not be protective; rather, professionals able to engage in self-care behaviours may have the material resources and self-capacities to take advantage of social support, potentially resulting from a secure attachment style.

Looking to individual risk factors such as attachment style or ACE history furthers understanding about why some individuals might be more or less impacted; however, such information is difficult to leverage at an organizational level. By widening the focus from professionals and STS to adult PTSD in general, meta-analytic findings offer more 
actionable results. According to two distinct meta-analyses, the strongest predictors of PTSD include trauma severity, life stress, lack of social support, and peritraumatic psychological processes (Brewin et al., 2000; Ozer et al., 2003). These results echo findings in the research looking specifically at child welfare indicating the degree of exposure to potentially traumatic experiences, unrealistic workloads, controlling organizational leadership, and the lack of administrative support as key risk factors (Cornille \& Meyers, 1999; Hiles Howard et al., 2015; Sprang et al., 2011; Van Hook \& Rothenberg, 2009). Given the importance of the organizational context, organizational strategies recommended to mitigate STS and workplace practices that influence peritraumatic psychological processes related to on-the-job trauma exposure will now be addressed.

\section{Promising organizational strategies to mitigate STS in child welfare}

Researchers investigating STS among child welfare professionals, and RCWs specifically, have offered implications related to the promotion of well-being that are well aligned with the meta-analytic findings related to PTSD risk and protective factors. In this literature, trauma severity and life stress appear to be correlated as do social support and strategies to ameliorate peritraumatic psychological processes.

Trauma severity and life stress. Research implications suggestive of strategies for the mitigation of trauma severity and life stress largely focused on the organizational role in providing environments and workplace structures responsive to employee needs. Following an analysis of thirteen organizations worldwide working with survivors of extreme trauma, Pross and Schweizer concluded that deficiencies in organizational structure were associated with high employee stress and conflict while organizations with clear organizational structures showed lower stress levels, less conflict, and lower post-traumatic symptoms (2010). Pross and Schweitzer described chaotic, unstructured, and unpredictable workplace environments as a parallel of "the total absence of structure that exists when a victim is at a perpetrator's disposal" (Pross \& Schweitzer, 2010, p. 102). Through this lens, the lack of conditions necessary towards the well-being of professionals can be considered akin to abuse.

Eastwood and Ecklund (2008) studied STS among 57 RCWs concluding that they needed time to take short breaks away from the children in their care, without threatening adequate staffing ratios. In their study of child protection social workers, Dagan et al. (2016) called for caseloads to be balanced and mitigated and for the establishments of clear role definitions and boundaries. Dombo and Blome (2016) interviewed directors of state child welfare organizations with local knowledge about organizational responses to STS. These participants championed the importance of enabling work-life balance amongst staff, with one state director sharing that they were moving towards becoming a trauma-informed organization (see the following section). All participants in this study acknowledged organizational structures, bureaucracy, and the political climates of their jurisdictions resulting in barriers to addressing STS, including having inadequate time, money, and staffing.

Social support and ameliorating peritraumatic psychological processes. McNamara (2010) interviewed ten staff members and two supervisors in an Australian residential youth justice facility and concluded there was a need for collaborative managerial approaches, incorporating a high degree of trust, reflection, systemic thinking, flexibility, and responsiveness. Hiles Howard et al. (2015) described a need for authoritative leadership rather than authoritarian leadership. Trust among the staff also emerged as an important aspect of social support (Dombo \& Blome, 2016; McNamara, 2010). Overall, a non-judgmental and caring workplace culture, where administrators were aware of the potential impacts of trauma exposure and staff were made to feel valuable to the organization, were considered optimal to promote professional well-being (Dombo \& Blome, 2016). A focus on organizational anticipation of the potential impacts of STS was cited in several studies and linked to preventive strategies: ensuring adequate vacations or leaves to allow time and resources for developing outside interests and social support systems (Eastwood \& Ecklund, 2008); creating organizational conditions to help workers process the negative impact of daily job stress-specifically exposure to details of child abuse and neglect (McNamara, 2010); taking steps to ensure that younger and single employees were provided with training and coping tools early in their career when they may need it most (Hiles Howard et al., 2015); raising awareness of risks associated with PTSD within the organization (Dagan et al., 2016); providing adequate training to all staff(Dombo \& Blome, 2016; Eastwood \& Ecklund, 2008); encouraging and providing resources to process personal trauma, including physical and psychological diagnostic and therapeutic services (Dagan et al., 2016; Dombo \& Blome, 2016; Eastwood \& Ecklund, 2008).

The need for supervision also emerged as an important implication for RCWs. Eastwood and Ecklund (2008) called for time to consult with peers and obtain supervision; while McNamara (2010) argued the need for individual access to supervision, supervision groups, individual and group debriefings, and advocacy on behalf of staff by 
supervisors. Bride and Jones (2006) surveyed child welfare case managers and supervisors in a southern American jurisdiction ( $n=307)$, concluding supervisors who were willing to help when problems arose, provide visible, ongoing support for innovations, ideas, and assistance to enhance quality of services were valued. It was not simply the availability of supervision that was important but also that it was considered to be of quality and occurred on a regular basis (Bride \& Jones, 2006; Dombo \& Blome, 2016). Participants in McNamara (2010) valued supervision that nurtured, affirmed, and normalized their experiences. These findings suggest that not all supervision was desirable or effective. Indeed, there are important caveats in the discussion of what strategies should be encouraged for RCWs.

Bober and Regehr (2006) surveyed 259 professionals, including RCWs, in southern Ontario. Consistent with meta-analytic findings related to risk factors for PTSD, they also found that the degree of severe trauma exposure was related to higher STS scores. Their findings also revealed "no association between time devoted to leisure, self-care, research and development, or supervision and traumatic stress scores" (p. 7). They concluded there was no evidence to suggest that using coping strategies often recommended in the extant literature were protective against symptoms of acute distress. In light of these findings, strategies that download coping with STS onto individual professionals in the form of self-care, education, or attending supervision cannot be considered adequate. STS must be considered a routine workplace hazard and human service organizations, including child welfare, must be made responsible for workplace safety-beyond physical safety related to violence, injury, or environmental toxins. In recent years a novel paradigm of practice embedded with a philosophy and evidence-based practices specifically aimed to reduce suffering related to interpersonal trauma has emerged. Perhaps most unique is that this model of practice not only considers the well-being of those served within the child welfare system, but those who work within it, and the organization itself.

\section{Trauma-informed care}

$\mathrm{TIC}$ is proposed as a double-pronged strategy to promote the recovery of children within the child welfare system, and to reduce harm caused by indirect trauma exposure to child-welfare professionals (Blaustein \& Kinniburgh, 2018; Bloom \& Farragher, 2013; Strand \& Sprang, 2018). The assumptions of a trauma-informed organization are that it "realizes the widespread impact of trauma and understands potential paths for recovery; recognizes the signs and symptoms of trauma in clients, families, staff, and others involved with the system; responds by fully integrating knowledge about trauma into policies, procedures, and practices, and seeks to actively resist re-traumatization" (SAMHSA's Trauma and Justice Strategic Initiative, 2014, p. 9). This framework is used to create an organizational culture that recognizes the ubiquity of trauma in the development of altered neurodevelopment and compromised immune responses, traumatic stress symptoms, maladaptive behaviors, and impaired functioning in those with toxic levels of exposure (direct and indirect) (Felitti et al., 1998; Shonkoff et al., 2012). Professionals operating in a trauma-informed manner use this knowledge as well as data on effective treatment in a process of delivering care that minimizes trauma reminders, prevents additional harms, and promotes healing and recovery (Foa et al., 2009). This is important as the literature is replete with examples of trauma-inducing practices in child serving organizations and systems; the iatrogenic trauma of placement disruptions, high staff turnover, harsh disciplinary practices, the use of seclusion and restraints, and other coercive or intimidating behaviors (Bloom \& Farragher, 2011; Mor Barak et al., 2001; SAMHSA's Trauma and Justice Strategic Initiative, 2014). A TIC model offers an alternative to these deleterious practices, and creates opportunities for healing and recovery informed by several decades of discoveries in clinical research on child traumatic stress treatment, practice generated knowledge of how to treat trauma, and lessons-learned from survivors (Cohen, 2010; Foa et al., 2009). TIC promotes and sustains the effective use of evidence-based, trauma specific treatments and practices by creating an environment that can sustain the implementation of such interventions, and a workforce that can deliver and sustain them effectively (Hummer et al., 2010).

For residential treatment centers to be trauma-informed, a workforce development and protection strategy that is in alignment with the values and principles of this approach to care is fundamental. Residential treatment centers must apply the same principles of TIC to the child welfare staff if they expect these professionals to deliver such services to children and youth. This is accomplished by creating an environment that realizes the impact of indirect trauma on the workforce, employs methods to recognize when STS is negatively affecting worker functioning, responds by enhancing worker resiliency and enhancing skill development to address distress, and resists re-traumatizing its workers by managing unnecessary threats and exposures. This approach is echoed by leading organizations and agencies that note the prevention and treatment of secondary trauma is essential for providing quality care to trauma exposed populations, and an important strategy for preventing turnover and increasing workforce retention (Cook \& Newman, 2014; Kim \& Kao, 2014; NCTSN Core Curriculum on Childhood Trauma Task Force, 2012; SAMHSA's Trauma 
and Justice Strategic Initiative, 2014). Failure to include STS prevention and intervention strategies into any TIC initiative in a residential setting would represent a barrier to effective implementation of any evidence-based or promising practice and would ultimately undermine the success of the agency in providing the most effective services to children.

In an attempt to operationalize an organization's role in workforce development and protection around this issue, the Secondary Traumatic Stress Informed Organizational Assessment (STSI-OA) was developed (Sprang et al., 2017) based on the literature on organizational change and development (Crossan et al., 1999), and a developmental perspective on TIC (Missouri Department of Mental Health and Partners, 2014) (see Figure 1). This tool articulates organizational strategies in the action domains of resilience building activities; the promotion of worker safety; the capacity of an organization to assess and evaluate policies for addressing and preventing secondary trauma exposures in real time; organizational and leadership practices to promote and address secondary trauma; and assessment and monitoring efforts (Cook \& Newman, 2014; Sprang et al., 2017). Since individuals are the primary stakeholders in an organization, the STSI-OA is most helpful if multiple reporters, representing different points in the organizational hierarchy, complete the assessment. This provides the most nuanced perspective on the organization and gives voice to the workforce. Between and within group comparisons can be conducted to detect perceptual and behavioral differences, communication gaps, and units with the highest levels of need for intervention and support. The results of the STSI-OA are a blueprint for training, and a data-driven strategy to guide organizations who are applying the principles of TIC to their workforce.

Figure 1. A model for organizational trauma-informed care

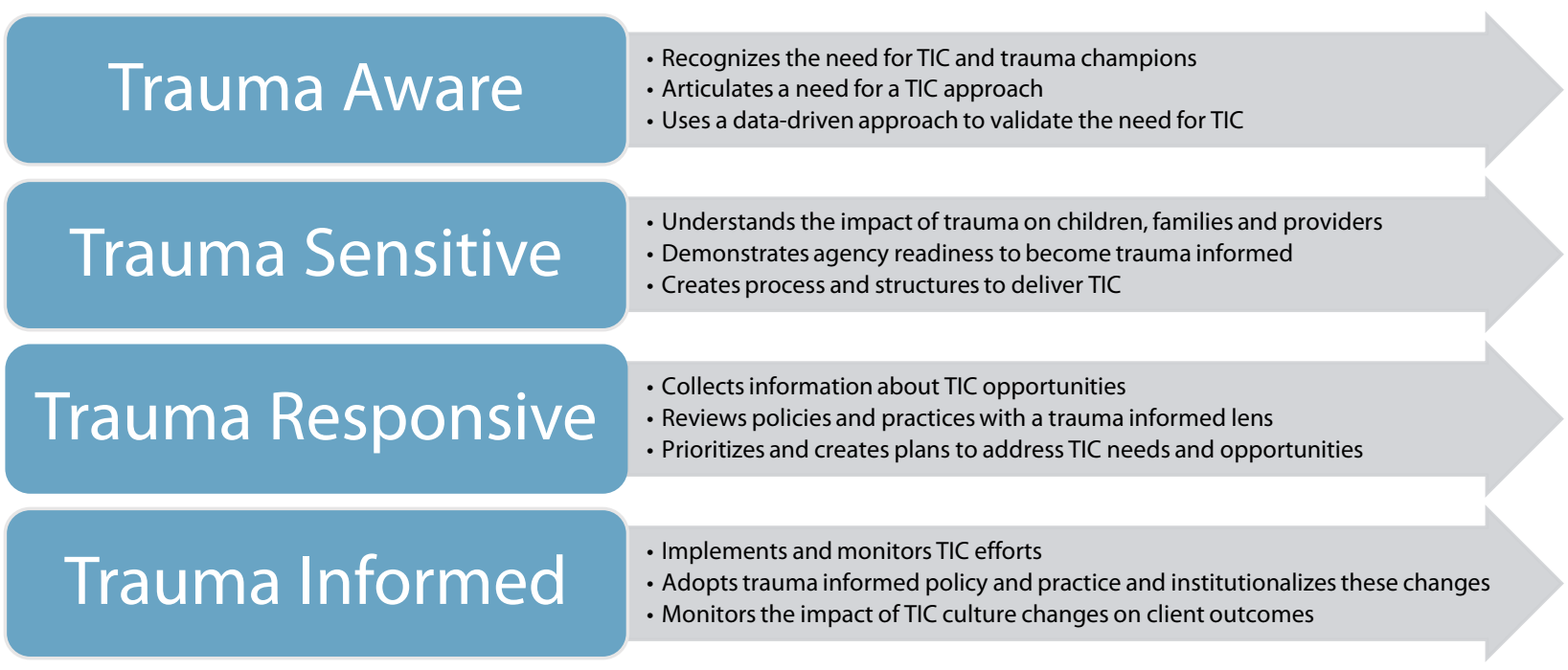

Note: Phased based approach is adopted from Missouri Department of Health and Partners (2014)

In best practice, these organizational approaches are executed in tandem with individual level actions such as self-monitoring and self-care, resilience building, the execution of practice behaviors to facilitate real-time processing of indirect trauma experiences (Miller \& Sprang, 2017), and the utilization of evidence-based trauma treatment when necessary (Sprang et al., 2019). A growing body of literature documents the important role of supervisors as boundary spanners who integrate these organizational and individual approaches. The literature supports the importance of this function, specifically in the areas of task assistance, social and emotional support, and the development of healthy supervisory-worker relationships (Choi, 2011a; Mor Barak et al., 2009). Recently, the National Child Traumatic Stress Network (2018) published a document, STS Informed Competencies for Trauma-informed Supervision that articulates the nine skill domains that would reflect competent supervision to reduce STS. These competencies reflect empirical research on what makes supervision effective in a trauma-informed environment, and includes knowledge and skill building around understanding and responding to STS in oneself and others, the capacity for co-regulation and to teach self-regulatory skills, reflective practice, using a trauma lens to guide supervision and crisis response, and the appropriate use of self-disclosure. Research is needed to determine the effectiveness of this translational tool on the quality of supervision and the STS of RCWs. 


\section{Conclusion}

RCWs fulfill a critical role in the security and development of children in need of residential placement. Ironically, it is through these helping relationships that RCWs can also be exposed to multiple potentially traumatic experiences. The workforce, like those it serves, is a living system that requires a standard of safety and protection to function properly. Indeed, RCWs have been shown to suffer traumatization at overwhelming rates. Recent research suggests the well-being of RCWs and the well-being of the children in their care are linked in a dynamic and reciprocal relational system. Despite all previous efforts, longstanding problems retaining staff in residential child welfare services have persisted and, in many jurisdictions, worsened over time. Child welfare appears to require a novel and systemwide response to improve outcomes for children and staff. TIC offers evidence-based, comprehensive approaches to guide child welfare practices and targeted intervention strategies to respond to the immediate needs faced by children and staff. In this way, TIC provides the foundation for reducing and addressing harms to staff, so that the promise of the approach can benefit children in residential care.

\section{Funding}

Université de Sherbrooke \& MITACS Acceleration Postdoctoral Fellowship.

\section{Conflict of interest}

The authors have no conflict of interest to disclose.

\section{References}

American Psychiatric Association. (2013a). Diagnostic and Statistical Manual of Mental Disorders: DSM-5. American Psychiatric Association.

American Psychiatric Association. (2013b). Posttraumatic Stress Disorder. In Diagnostic and Statistical Manual of Mental Disorders: DSM-5. American Psychiatric Association.

American Psychiatric Association. (2013c). Trauma-and stressor-related disorders. In Diagnostic and Statistical Manual of Mental Disorders: DSM-5. American Psychiatric Association.

Audin, K., Burke, J., \& Ivtzan, I. (2018). Compassion fatigue, compassion satisfaction and work engagement in residential child care. Scottish Journal Residential Child Care, 17(3), 1-25. https://www.celcis.org/files/8715/3719/1694/2018_Vol_17_No_3_Audin_K_Compassion_fatigue_compassion_satisfaction_ and_work_engagement_in_residential_childcare.pdf

Baglivio, M. (2018). On cumulative childhood traumatic exposure and violence/ aggression: The implications of Adverse Childhood Experiences (ACE). In A. Vazsonyi, D. Flannery, \& M. DeLisi (Eds.), The Cambridge Handbook of Violent Behavior and Aggression (Vol. 2). Cambridge University Press. https://doi.org/10.1017/9781316847992.027

Beebe, B., \& Lachman, F. (2002). Co-constructiong inner and relational processes: Self and interactive regulation in infant research and adult treatment. In Infant Reseach and Adult Treatment (pp. 121-142). Analytic Press.

Blaustein, M., \& Kinniburgh, K. (2018). Treating traumatic stress in children and adolescents: How to foster resilience through attachment, self-regulation, and competency (Second ed.). Guilford Publications.

Bloom, S., \& Farragher, B. (2011). Destroying sanctuary: The crisis in human service delivery systems. Oxford University Press. https://doi.org/10.1093/acprof:oso/9780195374803.001.0001

Bloom, S., \& Farragher, B. (2013). Restoring sanctuary: A new operating system for trauma-informed systems of care. Oxford University Press. https://doi.org/10.1093/acprof:oso/9780199796366.001.0001

Bober, T., \& Regehr, C. (2006). Strategies for reducing secondary or vicarious trauma: Do they work? Brief Treatment and Crisis Intervention, 6(1), 1-9. https://doi.org/10.1093/brief-treatment/mhj001

Borjanić Bolić, E. (2019). Secondary traumatic stress and vicarious traumatization in child welfare professionals in Serbia. Journal of Public Child Welfare, 13(2), 214-233. https://doi.org/10.1080/15548732.2018.1502117

Bowlby, J. (1988). A secure base: Parent-child attachment and healthy human development. Routledge.

Boyas, J., Wind, L., \& Kang, S. (2012). Exploring the relationship between employment-based social capital, job stress, burnout, and intent to leave among child protection workers: An age-based path analysis model. Children and Youth Services Review, 34(1), 50-62. https://doi.org/10.1016/j.childyouth.2011.08.033 
Brandt, K., Perry, B., Seligman, S., Tronick, E., \& American Psychiatric Association. (2014). Infant and early childhood mental health : core concepts and clinical practice (First edition. ed.). American Psychiatric Publishing.

Brend, D. M., Fletcher, K., \& Nutton, J. (2013). With Laura: Attachment and the healing potential of substitute caregivers within crosscultural child welfare practice. First Peoples Child \& Family Review, 7(2), 43-59.

Brend, D. M., Lanctôt, N., \& Geoffrion, S. (2020). Moral distress among residential care workers. Unpublished manuscript.

Brewin, C., Andrews, B., \& Valentine, J. (2000). Meta-analysis of risk factors for posttraumatic stress disorder in trauma-exposed adults. Journal of Consulting and Clinical Psychology, 68(5), 748-766. https://doi.org/10.1037/0022-006X.68.5.748

Bride, B. (2007). Prevalence of secondary traumatic stress among social workers. Social Work, 52(1), 63-70. https://doi.org/10.1093/sw/52.1.63

Bride, B., \& Jones, J. (2006). Secondary traumatic stress in child welfare workers: Exploring the role of supervisory culture. Professional Development: The International Journal of Continuing Social Work Education, 9(2), 38-43. http://www.profdevjournal.org/articles/92038.pdf

Briere, J., \& Scott, C. (2015). Principles of trauma therapy: A guide to symptoms, evaluation, and treatment (Second edition, DSM-5 update. ed.). Sage Publications.

Caringi, J., \& Hardiman, E. (2011). Secondary traumatic stress among child welfare workers in the United States. International Journal of Child \& Family Welfare, 14(2), 50-63.

Catalan, A., Angosto, V., Díaz, A., Valverde, C., de Artaza, M. G., Sesma, E., Maruottolo, C., Galletero, I, Bustamante, S., Bibao, A., van Os, J., \& Gonzalez-Torres, M. (2017). Relation between psychotic symptoms, parental care and childhood trauma in severe mental disorders. Psychiatry Research, 251, 78-84. https://doi.org/10.1016/j.psychres.2017.02.017

Chernesky, R., \& Israel, M. (2009). Job Expectations and intention to leave in a state child welfare agency. Journal of Public Child Welfare, 3(1), 23-39. https://doi.org/10.1080/15548730802690817

Child Welfare Research Portal. (2010). Information Sheet \#82E. University of Toronto, Faculty of Social Work.

Choi, G. (2011a). Organizational impacts on the secondary traumatic stress of social workers assisting family violence or sexual assault survivors. Administration in Social Work, 35(3), 225-242. https://doi.org/10.1080/03643107.2011.575333

Choi, G. (2011 b). Secondary traumatic stress of service providers who practice with survivors of family or sexual violence: A national survey of social workers. Smith College Studies in Social Work, 81(1), 101-119. https://doi.org/10.1080/00377317.2011.543044

Cieslak, R., Shoji, K., Douglas, A., Melville, E., Luszczynska, A., \& Benight, C. (2014). A meta-analysis of the relationship between job burnout and secondary traumatic stress among workers with indirect exposure to trauma. Psychological Services, 17(1), 7586. https://doi.org/10.1037/a0033798

Cohen, J. (2010). Practice parameter for the assessment and treatment of children and adolescents with posttraumatic stress disorder. Journal of the American Academy of Child \& Adolescent Psychiatry, 49(4), 414-430. https://doi.org/10.1016/j.jaac.2009.12.020

Cook, A., Spinazzola, J., Ford, J., Lanktree, C., Blaustein, M., Cloitre, M., DeRosa, R., Hubbard, R., Kagan, R., Liautaud, J., Mallah, K., Olafson, E., \& van der Kolk, B. (2005). Complex trauma in children and adolescents. Psychiatric Annals, 35(5), $390-398$. https://doi.org/10.3928/00485713-20050501-05

Cook, J., \& Newman, E. (2014). A consensus statement on trauma mental health: The New Haven Competency Conference process and major findings. Psychological Trauma: Theory, Research, Practice, and Policy, 6(4), $300-307$. https://doi.org/10.1037/a0036747

Cornille, T., \& Meyers, T. (1999). Secondary traumatic stress among child protective service workers: Prevalence, severity and predictive factors. Traumatology, 5(1). https://doi.org/10.1177/153476569900500105

Courtois, C., \& Ford, J. (2013). Treating complex trauma: A sequenced relationship-based approach. Guilford.

Crossan, M., Lane, H., \& White, R. (1999). An organizational learning framework: From intuition to institution. The Academy of Management Review, 24(3), 522-537. https://doi.org/10.5465/amr.1999.2202135

Dagan, S., Ben-Porat, A., \& Itzhaky, H. (2016). Child protection workers dealing with child abuse: The contribution of personal, social and organizational resources to secondary traumatization. Child Abuse \& Neglect, 51, $203-211$. https://doi.org/10.1016/j.chiabu.2015.10.008

Dombo, E., \& Blome, W. (2016). Vicarious trauma in child welfare workers: A study of organizational responses. Journal of Public Child Welfare, 105), 505-523. https://doi.org/10.1080/15548732.2016.1206506

DuRoss, C., Fallon, B., \& Black, T. (2019). Group home and residential treatment placements in child welfare: Analyzing the 2003 Canadian Incidence Study of Reported Child Abuse and Neglect (CIS-2003). Canada's Children, 16(3), 67-76.

Eastwood, C., \& Ecklund, K. (2008). Compassion fatigue risk and self-care practices among residential treatment center childcare workers. Residential Treatment for Children \& Youth, 25(2), 103-122. https://doi.org/10.1080/08865710802309972 
Felitti, V., Anda, R., Nordenberg, D., Williamson, D., Spitz, A., Edwards, V., Koss, M. P., \& Marks, J. (1998). Relationship of childhood abuse and household dysfunction to many of the leading causes of death in adults: The Adverse Childhood Experiences (ACE) Study. American Journal of Preventive Medicine, 14(4), 245-258. https://doi.org/10.1016/S0749-3797(98)00017-8

Figley, C. (1995). Compassion fatigue: Coping with secondary traumatic stress disorder in those who treat the traumatized. Bruner/ Mazel.

Foa, E., Keane, T., Friedman, M., \& Cohen, J. (2009). Effective treatments for PTSD: Practice guidelines from the International Society for Traumatic Stress Studies. Guilford Press.

Follette, V., Polusny, M., \& Milbeck, K. (1994). Mental health and law enforcement professionals: Trauma history, psychological symptoms, and impact of providing services to child sexual abuse survivors. Professional Psychology: Research and Practice, 25(3), 275-282. https://doi.org/10.1037/0735-7028.25.3.275

Fonagy, P., \& Campbell, C. (2015). Bad blood revisited: Attachment and psychoanalysis, 2015. British journal of psychotherapy, 31(2), 229-250. https://doi.org/10.1111/bjp.12150

Ford, J. (2014). Neurobiological and developmental research: Clinical implications. In C. A. Courtois \& J. D. Ford (Eds.), Treating Complex Traumatic Stress Disorders: Scientific foundations and therapeutic models. Guilford Press.

Ford, J., Chapman, J., Connor, D., \& Cruise, K. (2012). Complex trauma and aggression in secure juvenile justice settings. . Criminal Justice and Behavior, 39, 694-724. https://doi.org/10.1177/0093854812436957

Geoffrion, S., \& Ouellet, F. (2013). Quand la réadaptation blesse? Éducateurs victimes de violence. Criminologie, 46(2), $263-289$. https://doi.org/10.7202/1020996ar

Graef, M., \& Hill, E. (2000). Costing child protective services staff turnover. Child Welfare League of America, 79(5), 517-533.

Hébert, S., Lanctôt, N., \& Turcotte, M. (2016). "I didn't want to be moved there": Young women remembering their perceived sense of Agency in the Context of placement instability. Children and Youth Services Review, 70, $229-237$. https://doi.org/10.1016/j.childyouth.2016.09.029

Hiles Howard, A., Parris, S., Hall, J., Call, C., Razuri, E., Purvis, K., \& Cross, D. (2015). An examination of the relationships between professional quality of life, adverse childhood experiences, resilience, and work environment in a sample of human service providers. Children and Youth Services Review, 57, 141-148. https://doi.org/10.1016/j.childyouth.2015.08.003

Hummer, V., Dollard, N., Robst, J., \& Armstrong, M. (2010). Innovations in implementation of trauma-informed care practices in youth residential treatment: A curriculum for organizational change. Child Welfare, 89(2), 79-95.

Itzick, M., \& Kagan, M. (2017). Intention to leave the profession: Welfare social workers compared to health care and community social workers in Israel. Journal of Social Service Research, 43(3), 346-357. https://doi.org/10.1080/01488376.2016.1246402

Kassam-Adams, N. (1998). The Risks of Treating Sexual Trauma: Stress and Secondary Trauma in Psychotherapists. In B. H. Stamm (Ed.), Secondary Traumatic Sress: Self-care issues for clinicians, researchers and educators. Sidran Press.

Kessler, R., Berglund, P., Demler, O., Jin, R., Merikangas, K., \& Walters, E. (2005). Lifetime prevalence and age-of-onset distributions of dsm-iv disorders in the national comorbidity survey replication. Archives of General Psychiatry, 62(6), $593-602$. https://doi.org/10.1001/archpsyc.62.6.593

Kim, H., \& Kao, D. (2014). A meta-analysis of turnover intention predictors among U.S. child welfare workers. Children and Youth Services Review, 47, 214-223. https://doi.org/10.1016/j.childyouth.2014.09.015

Lakin, B., Leon, S., \& Miller, S. (2008). Predictors of burnout in children's residential treatment center staff. Residential Treatment for Children \& Youth, 25(3), 249-270. https://doi.org/10.1080/08865710802429697

Lamothe, J., Couvrette, A., Lebrun, G., Yale-Soulière, G., Roy, C., Guay, S., \& Geoffrion, S. (2018). Violence against child protection workers: A study of workers' experiences, attributions, and coping strategies. Child Abuse \& Neglect, 81, $308-321$. https://doi.org/10.1016/j.chiabu.2018.04.027

Littlechild, B. (2005). The nature and effects of violence against child-protection social workers: Providing effective support. The British Journal of Social Work, 35(3), 387-401. https://doi.org/10.1093/bjsw/bch188

Lünnemann, M., Horst, F., Prinzie, P., Luijk, M., \& Steketee, M. (2019). The intergenerational impact of trauma and family violence on parents and their children. Child Abuse \& Neglect, 96, Article 104134. https://doi.org/10.1016/j.chiabu.2019.104134

Madden, E., Scannapieco, M., \& Painter, K. (2014). An examination of retention and length of employment among public child welfare workers. Children and Youth Services Review, 41(0), 37-44. https://doi.org/10.1016/j.childyouth.2014.02.015

McCann, I., \& Pearlman, L. (1990). Vicarious traumatization: A framework for understanding the psychological effects of working with victims. Journal of Traumatic Stress, 3(1), 131-149. https://doi.org/10.1002/jts.2490030110

McElvaney, R., \& Tatlow-Golden, M. (2016). A traumatised and traumatising system: Professionals' experiences in meeting the mental health needs of young people in the care and youth justice systems in Ireland. Children and Youth Services Review, 65, 62-69. https://doi.org/10.1016/j.childyouth.2016.03.017 
McGowan, B., Auerbach, C., \& Strolin-Goltzman, J. (2009). Turnover in the Child Welfare Workforce: A different perspective. Journal of Social Service Research, 35(3), 228-235. https://doi.org/10.1080/01488370902900782

McNamara, P. (2010). Staff support and supervision in residential youth justice: An australian model. Residential Treatment for Children \& Youth, 27(3), 214-240. https://doi.org/10.1080/0886571X.2010.501630

Middleton, J., \& Potter, C. (2015). Relationship between vicarious traumatization and turnover among child welfare professionals. Journal of Public Child Welfare, 9(2), 195-216. https://doi.org/10.1080/15548732.2015.1021987

Miller, B., \& Sprang, G. (2017). A components-based practice and supervision model for reducing compassion fatigue by affecting clinician experience. Traumatology, 23(2), 153-164. https://doi.org/10.1037/trm0000058

Missouri Department of Mental Health and Partners. (2014). The Missouri Model: A developmental framework for trauma-informed approaches.

Molnar, B., Sprang, G., Killian, K., Gottfried, R., Emery, V., \& Bride, B. (2017). Advancing science and practice for vicarious traumatization/secondary traumatic stress: A research agenda. Traumatology, 23(2), $129-142$. https://doi.org/10.1037/trm0000122

Mor Barak, M., Nissly, J., \& Levin, A. (2001). Antecedents to retention and turnover among child welfare, social work, and other human service employees: What can we learn from past research? A review and metanalysis. Social Service Review, 75(4), 625-661. https://doi.org/10.1086/323166

Mor Barak, M., Travis, D., Pyun, H., \& Xie, B. (2009). The impact of supervision on worker outcomes: A meta-analysis. Social Service Review, 83(1), 3-32. https://doi.org/10.1086/599028

National Child Traumatic Stress Network. (2018). STS-Informed Competencies for Trauma-Informed Supervision. Retrieved from https://www.nctsn.org/sites/default/files/resources/fact-

sheet/using_the_secondary_traumatic_stress_core_competencies_in_trauma-informed_supervision.pdf

NCTSN Core Curriculum on Childhood Trauma Task Force. (2012). The 12 core concepts: Concepts for understanding traumatic stress responses in children and families, Core curriculum on childhood trauma. UCLA-Duke University National Center for Child Traumatic

Stress. https://www.nctsn.org/sites/default/files/resources//the_12_core_concepts_for_understanding_traumatic_stress_response s_in_children_and_families.pdf

Nissly, J., Barak, M., \& Levin, A. (2005). Stress, social support, and workers' intentions to leave their jobs in public child welfare. Administration in Social Work, 29(1), 79-100. https://doi.org/10.1300/J147v29n01_06

Ozer, E., Best, S., Lipsey, T., \& Weiss, D. (2003). Predictors of posttraumatic stress disorder and symptoms in adults: A meta-analysis. Psychological Bulletin, 129(1), 52-73. https://doi.org/10.1037/0033-2909.129.1.52

Pearlman, L., \& Courtois, C. (2005). Clinical applications of the attachment framework: Relational treatment of complex trauma. Journal of Traumatic Stress, 18(5), 449-459. https://doi.org/10.1002/jts.20052

Pross, C., \& Schweitzer, S. (2010). The culture of organizations dealing with trauma: Sources of work-related stress and conflict. Traumatology, 16(4), 97-108. https://doi.org/10.1177/1534765610388301

Pryce, J., Shackelford, K., \& Pryce, D. (2007). Secondary traumatic stress and the child welfare professional. Lyceum Books.

Regehr, C., Leslie, B., Howe, P., \& Chau, S. (2005). Stress, trauma, and support in child welfare practice. APSAC Advisor, 172), $12-18$.

Robson, A., Cossar, J., \& Quayle, E. (2014). Critical commentary: The impact of work-related violence towards social workers in children and family services. British Journal of Social Work, 44(4), 924-936. https://doi.org/10.1093/bjsw/bcu015

Salloum, A., Kondrat, D., Johnco, C., \& Olson, K. (2015). The role of self-care on compassion satisfaction, burnout and secondary trauma among child welfare workers. Children and Youth Services Review, 49(2), 54-61. https://doi.org/10.1016/j.childyouth.2014.12.023

SAMHSA's Trauma and Justice Strategic Initiative. (2014). SAMHSA's Concept of Trauma and Guidance for a Trauma-Informed Approach. (HHS Publication No. (SMA) 14-4884). Substance Abuse and Mental Health Services Administration. https://ncsacw.samhsa.gov/userfiles/files/SAMHSA_Trauma.pdf

Schauben, L., \& Frazier, P. (1995). Vicarious Trauma: The effects on female counselors of working with sexual violence survivors. Psychology of Women Quarterly, 1911), 49-64. https://doi.org/10.1111/j.1471-6402.1995.tb00278.x

Shin, J. (2011). Client violence and its negative impacts on work attitudes of child protection workers compared to community service workers. Journal of Interpersonal Violence, 26(16), 3338-3360. https://doi.org/10.1177/0886260510393002

Shonkoff, J., Garner, A., Committee on Psychosocial Aspects of Child and Family Health, Committee on Early Childhood, Adoption, and Dependent Care, \& Section on Developmental and Behavioral Pediatrics. (2012). The lifelong effects of early childhood adversity and toxic stress. Pediatrics, 129(1), 232-246. https://doi.org/10.1542/peds.2011-2663 
Slattery, S., \& Goodman, L. (2009). Secondary traumatic stress among domestic violence advocates: Workplace risk and protective factors. Violence Against Women, 15(11), 1358-1379. https://doi.org/10.1177/1077801209347469

Spinazzola, J., Ford, J., Zucker, M., van der Kolk, B., Silva, S., Smith, S., \& Blaustein, M. (2005). Survey evaluates: Complex trauma exposure, outcome, and intervention among children and adolescents. Psychiatric Annals, 35(5), $433-439$. https://doi.org/10.3928/00485713-20050501-09

Sprang, G., Craig, C., \& Clark, J. (2011). Secondary traumatic stress and burnout in child welfare workers: A comparative analysis of occupational distress across professional groups. Child Welfare, 906), 149-168.

Sprang, G., Ford, J., Kerig, P., \& Bride, B. (2019). Defining secondary traumatic stress and developing targeted assessments and interventions: Lessons learned from research and leading experts. Traumatology, 25(2), $72-81$. https://doi.org/10.1037/trm0000180

Sprang, G., Ross, L., Miller, B., Blackshear, K., \& Ascienzo, S. (2017). Psychometric properties of the Secondary Traumatic Stress-Informed Organizational Assessment. Traumatology, 23(2), 165-171. https://doi.org/10.1037/trm0000108

Stamm, B. (1995). Secondary Traumatic Stress: Self-care issues for clinicians, researchers and educators. Sidran Press.

Strand, V., \& Sprang, G. (2018). Trauma responsive child welfare systems. Springer. https://doi.org/10.1007/978-3-319-64602-2

Strolin, J., McCarthy, M., \& Caringi, J. (2006). Causes and effects of child welfare workforce turnover. Journal of Public Child Welfare, 1(2), 29-52. https://doi.org/10.1300/J479v01n02_03

Strolin-Goltzman, J., Kollar, S., \& Trinkle, J. (2010). Listening to the voices of children in foster care: Youths speak out about child welfare workforce turnover and selection. Social Work, 55(1), 47-53. https://doi.org/10.1093/sw/55.1.47

Tollen, W. (1960). Study of Staff Losses in Child Welfare and Family Services Agencies. U.S. Department of Health Edication, and Welfare.

Tremblay, C., Haines, V., \& Joly, J. (2016). Staff Turnover and Service Quality Within Residential Settings. Human Service Organizations: Management, Leadership \& Governance, 4O(1), 22-36. https://doi.org/10.1080/23303131.2015.1085479

Ungar, M. (2005). Pathways to resilience among children in child welfare, corrections, mental health and educational settings: Navigation and negotiation. Child and Youth Care Forum, 34(6), 423-444. https://doi.org/10.1007/s10566-005-7755-7

Ungar, M. (2013). Resilience after maltreatment: The importance of social services as facilitators of positive adaptation. Child Abuse \& Neglect, 37(2), 110-115. https://doi.org/10.1016/j.chiabu.2012.08.004

van der Hart, O., Nijenhuis, E., \& Steele, K. (2005). Dissociation: An insufficiently recognized major feature of complex posttraumatic stress disorder. Journal of Traumatic Stress, 18(5), 413-423. https://doi.org/10.1002/jts.20049

van der Kolk, B., Roth, S., Pelcovitz, D., Sunday, S., \& Spinazzola, J. (2005). Disorders of extreme stress: The empirical foundation of a complex adaptation to trauma. Journal of Traumatic Stress, 18(5), 389-399. https://doi.org/10.1002/jts.20047

Van Hook, M., \& Rothenberg, M. (2009). Quality of life and compassion satisfaction/fatigue and burnout in child welfare workers: A Study of the child welfare workers in community based care organizations in central florida. Social Work \& Christianity, 36(1), 36-54.

West, A. (2015). Associations among attachment style, burnout, and compassion fatigue in health and human service workers: A systematic review. Journal of Human Behavior in the Social Environment, 25(6), 571-590. https://doi.org/10.1080/10911359.2014.988321

Zerach, G. (2013). Compassion fatigue and compassion satisfaction among residential child care workers: The role of personality Resources. Residential Treatment for Children \& Youth, 30(1), 72-91. https://doi.org/10.1080/0886571X.2012.761515 